\title{
Multiple Functions of RNA Methylation in T Cells: A Review
}

\author{
Yinong Chao ${ }^{1,2}$, Hua-Bing $\mathrm{Li}^{1,2 *}$ and Jing Zhou ${ }^{1,2 *}$ \\ 1 Shanghai Institute of Immunology, State Key Laboratory of Oncogenes and Related Genes, Shanghai Jiao Tong University \\ School of Medicine, Shanghai, China, ${ }^{2}$ Shanghai Jiao Tong University School of Medicine - Yale Institute for Immune \\ Metabolism, Shanghai Jiao Tong University School of Medicine, Shanghai, China
}

OPEN ACCESS

Edited by:

Li-Fan Lu,

University of California, San Diego, United States

Reviewed by:

HsinYue Tsai,

National Taiwan University, Taiwan

Dipayan Rudra,

Pohang University of Science and Technology, South Korea

${ }^{*}$ Correspondence:

Jing Zhou

jingzhou@shsmu.edu.cn

Hua-Bing Li

huabing.li@shsmu.edu.cn

Specialty section:

This article was submitted to

T Cell Biology,

a section of the journal

Frontiers in Immunology

Received: 09 November 2020

Accepted: 22 March 2021

Published: 12 April 2021

Citation:

Chao Y, Li HB and Zhou J (2021)

Multiple Functions of RNA

Methylation in T Cells: A Review.

Front. Immunol. 12:627455.

doi: 10.3389/fimmu.2021.627455
RNA modification represents one of the most ubiquitous mechanisms of epigenetic regulation and plays an essential role in modulating cell proliferation, differentiation, fate determination, and other biological activities. At present, over 170 types of RNA modification have been discovered in messenger RNA (mRNA) and noncoding RNA (ncRNA). RNA methylation, as an abundant and widely studied epigenetic modification, is crucial for regulating various physiological or pathological states, especially immune responses. Considering the biological significance of $T$ cells as a defense against viral infection and tumor challenge, in this review, we will summarize recent findings of how RNA methylation regulates T cell homeostasis and function, discuss the open questions in this rapidly expanding field of RNA modification, and provide the theoretical basis and potential therapeutic strategies involving targeting of RNA methylation to orchestrate beneficial $\mathrm{T}$ cell immune responses.

Keywords: RNA methylation, $\mathrm{m}^{6} \mathrm{~A}, \mathrm{~T}$ cell, epigenetics, immune function

\section{INTRODUCTION}

Over 170 types of RNA modifications have been identified to date, which have allowed to expand the RNA code, giving rise to a new field called "RNA epigenetics" (1-3). Dynamic chemical modifications alter the structure and metabolism of coding and non-coding RNAs post-transcriptionally (1-3). As mass spectrometry and high throughput technology continue to be developed, these modifications can be studied more broadly and deeply. Among these modifications, RNA methylation is an important post-transcriptional regulation and comprises diverse forms of methylation, including $N^{6}$-methyladenosine $\left(\mathrm{m}^{6} \mathrm{~A}\right), N^{6}$-2'-O-dimethyladenosine $\left(\mathrm{m}^{6} \mathrm{Am}\right), N^{1}$-methyladenosine $\left(\mathrm{m}^{1} \mathrm{~A}\right)$, and 5 -methylcytosine $\left(\mathrm{m}^{5} \mathrm{C}\right)(3)$. With the identification of different methyltransferase and demethylase enzymes, the physiological and pathological functions of RNA methylation have been gradually revealed, and have become an attractive area of research $(4,5)$.

The methylation of RNA represents one of the most ubiquitous modifications in mammalian cells and modulates multiple biological functions, especially innate and adaptive immune responses $(6,7)$. As crucial components of adaptive immunity, T cells are ready to prompt response to the foreign stimuli and mediate antiviral and antitumor immune responses $(8,9)$. Considering the importance of $\mathrm{T}$ cells' immunological surveillance in the body and dynamic RNA methylation usually occurs in a very short time to initiate the regulatory role toward the target genes, it will be 
interesting to utilize T cell as an ideal model to understand how RNA epigenetic modifications quickly affect immune responses.

In this review, we will outline recent findings regarding the role of RNA methylation in regulating $\mathrm{T}$ cell function, highlight current challenges in these areas, and clarify the potential application of RNA methylation in orchestrating $\mathrm{T}$ cell immune responses.

\section{RNA METHYLATION IN T CELLS}

Methylation of RNA is indispensable for the biogenesis and function of prokaryotes and eukaryotes (10). This modification is widely distributed in messenger RNA (mRNA), transfer RNA (tRNA), ribosomal RNA (rRNA), noncoding small RNA (sncRNA), and long-chain non-coding RNA (lncRNA) and can affect protein synthesis by regulating splicing, nuclear export, translation, and decay of RNA (10-13). With the discovery of $\mathrm{m}^{6} \mathrm{~A}$ and identification of its critical role in regulating immune responses, emerging evidence has stimulated researchers to explore how other major forms of RNA methylation may modulate the host immune system, especially $\mathrm{T}$ cell immunity, to expand the basic understanding of the epitranscriptomic code of RNA.

\section{$N^{6}$-methyladenosine $\left(\mathrm{m}^{6} \mathrm{~A}\right)$}

$\mathrm{m}^{6} \mathrm{~A}$ refers to methylation of adenosine (A) at the nitrogen- 6 position and represents one of the most frequent RNA modifications. It is preferentially enriched in 3'untranslated regions (3'UTR), long internal exons, and near stop codons of linear RNAs (14-16). The $\mathrm{m}^{6} \mathrm{~A}$ modification is dynamically reversibly installed and removed by methyltransferases ("writers") and demethylases ("erasers") (17). The "writer" complex contains three core proteins: methyltransferase-like 3 (METTL3) (18, 19), METTL14 (20, 21), and Wilms' tumor 1associating protein (WTAP) $(22,23)$. Other newly recognized regulators including vir-like $\mathrm{m}^{6} \mathrm{~A}$ methyltransferase associated (VIRMA, also called KIAA1429), RNA binding motif protein 15/ 15B (RBM15/15B), cbl-proto-oncogene-like protein 1 (CBLL1, also known as HAKAI), and Zinc finger CCCH-type containing 13 ( $\mathrm{ZC} 3 \mathrm{H} 13)$, are essential for the nuclear localization and stabilization of the "writer" complex, or $\mathrm{m}^{6} \mathrm{~A}$ deposition specificity (6). The two currently identified "erasers" are fat mass and obesity-associated protein (FTO) (24) and alkylated DNA repair protein AlkB homolog 5 (ALKBH5) (25). FTO not only functions as the demethylase for $\mathrm{m}^{6} \mathrm{~A}$ in mRNA, but also displays demethylase activity for $\mathrm{m}^{6} \mathrm{Am}$ and $\mathrm{m}^{1} \mathrm{~A}$ for specific tRNA, snRNA, or mRNA (26). Multiple proteins that bind to $\mathrm{m}^{6} \mathrm{~A}$, affect the fate of the corresponding RNA and its downstream functions and are referred to as $\mathrm{m}^{6} \mathrm{~A}$-binding proteins ("readers"). To date, three different groups of "readers" have been identified: YTH-RNA binding domain family, including three YTH-domain-family (YTHDF1-3) and two YTH domain-containing (YTHDC1-2) proteins (27-29), the heterogeneous nuclear ribonucleoprotein (HNRNP) family (3032) and insulin-like growth factor- 2 mRNA-biding proteins (IGF2BPs) $(33,34)$. All "readers" mediate regulatory functions of $\mathrm{m}^{6} \mathrm{~A}$ on modified RNA and participate in RNA splicing nuclear export and storage, translation, and decay (27-29) (Table 1).

$\mathrm{T}$ cells, generally comprising $\mathrm{CD}^{+} \mathrm{T}$ and $\mathrm{CD}^{+} \mathrm{T}$ cells, largely represent the foundation of the adaptive immune system. Naïve $\mathrm{CD}^{+}{ }^{+} \mathrm{T}$ cells exhibit features of stem cells, and will further differentiate into different $\mathrm{T}$ helper (Th) cell subsets upon stimulation by various microenvironmental signals $(35,36)$. Evidence from embryonic stem cells has indicated the importance of $\mathrm{m}^{6} \mathrm{~A}$ in determining stem cell fates (37), implying the potential of $\mathrm{m}^{6} \mathrm{~A}$ in directing $\mathrm{Th}$ cell differentiation. In 2017, our lab constructed a conditional knockout mouse model (Mettl $3^{\text {flox/flox }} \mathrm{Cd} 4^{\mathrm{Cre}}$ ) for $\mathrm{m}^{6} \mathrm{~A}$ writer protein-METTL3 in T cells, in the first attempt to elucidate the in vivo role of METTL3 and consequently the $\mathrm{m}^{6} \mathrm{~A}$ RNA modification in regulating mouse $\mathrm{T}$ cells homeostasis and differentiation (38). Characterization of immune cell populations at steady state of this mice model revealed that the ablation of METTL3 in T cells disrupted T cell homeostasis (38). Furthermore, METTL3-deficient naïve $\mathrm{CD}^{+} \mathrm{T}$ cells differentiated into fewer Th1 and Th17 cells, more Th2 cells, without affecting regulatory $\mathrm{T}$ cells (Tregs) induction compared with WT naïve $\mathrm{CD}^{+} \mathrm{T}$ cells (38). Interestingly, METTL3 or METTL14 also promoted naïve $\mathrm{CD}^{+} \mathrm{T}$ cell homeostatic expansion in vivo during the adoptive transfer colitis model (38). With these observations, we determined that the mRNAs of the suppressor of cytokine signaling (SOCS) family genes modified by $\mathrm{m}^{6} \mathrm{~A}$ underwent rapid mRNA degradation upon interleukin (IL)-7 stimulation, thus initiating the homeostasis and differentiation of naïve $\mathrm{T}$ cells by relieving the block on the IL-7-signal transducers and activators of transcription 5 (STAT5) pathway (38). Shortly after, our omics data was reevaluated by others, who comprehensively quantified the RNA

TABLE 1 | Writers, readers and erasers in predominant RNA methylations.

\begin{tabular}{|c|c|c|c|}
\hline $\begin{array}{l}\text { RNA } \\
\text { Modific }\end{array}$ & Writers & Erasers & Readers \\
\hline $\mathrm{m}^{6} \mathrm{~A}$ & $\begin{array}{l}\text { METTL3; METTL14; WTAP; VIRMA; RBM15/15B; CBLL1; } \\
\text { ZC3H13 }\end{array}$ & FTO; ALKBH5 & $\begin{array}{l}\text { YTH-RNA binding domain family (YTHDF1-3, YTHDC1-2); } \\
\text { heterogeneous nuclear ribonucleoprotein (HNRNP) family; } \\
\text { insulin-like growth factor-2 mRNA-biding proteins (IGF2BPs) }\end{array}$ \\
\hline$m^{6} \mathrm{Am}$ & $\mathrm{PClF} 1$ & FTO & Not defined \\
\hline $\mathrm{m}^{1} \mathrm{~A}$ & TRMT6/TRMT61A; TRMT61B; TRMT10C; NML & $\begin{array}{l}\text { FTO; ALKBH1; } \\
\text { ALKBH3 }\end{array}$ & YTHDF1-3; YTHDC1 \\
\hline$m^{5} \mathrm{C}$ & NSUN1-7; DNMT2 & Not defined & ALYREF; YBX1 \\
\hline
\end{tabular}


dynamics of $\mathrm{T}$ cell during differentiation, and showed that $\mathrm{m}^{6} \mathrm{~A}$ depletion impairs this process (39), further illustrating the importance of the epitranscriptomic $\mathrm{m}^{6} \mathrm{~A}$ modification, in governing $\mathrm{T}$ cell homeostasis and function.

Although in vitro evidence suggests the dispensable role of METTL3 in directing Tregs differentiation by a $\mathrm{T}$ cell receptor (TCR)-dependent $\mathrm{T}$ cell induction system (38), whether $\mathrm{m}^{6} \mathrm{~A}$ modification affects Tregs functions in vivo is still unclear. After observing that $\mathrm{Mettl} 3^{\text {flox/flox }} \mathrm{Cd} 4^{\mathrm{Cre}}$ mice developed spontaneous chronic inflammation in the intestine after 3 months of age, we hypothesized that Tregs might have impaired repressive functions in these mice (40). Therefore, we bred Mettl $3^{\text {flox/ }}$ ${ }^{\text {flox }}$ Foxp $3^{\text {Cre }}$ mice to specifically delete METTL3 expression in Tregs, and observed the development of severe systemic autoimmune diseases of the mice soon after weaning. The mice began to die at the ages of 8-9 weeks old, which was attributed to the systematic loss of Tregs suppressive function lacking $\mathrm{m}^{6} \mathrm{~A}$ modification (40). Mechanistically, the METTL3-mediated $\mathrm{m}^{6} \mathrm{~A}$ RNA modification specifically targets the SOCS gene family and sustains the suppressive functions of Tregs via the IL2-STAT5 pathway (40). The findings further implied that $\mathrm{T}$ cell-specific delivery of $\mathrm{m}^{6} \mathrm{~A}$-modifying agents might be employed in treating autoimmune disorders.

$\mathrm{T}$ follicular helper $\mathrm{T}(\mathrm{Tfh})$ cells, as a specialized $\mathrm{CD}^{+} \mathrm{T}$ cell subset, initiate germinal center (GC) formation and promote humoral immunity (41), whether their lineage differentiation can be directed by $\mathrm{m}^{6} \mathrm{~A}$ modification remains to be identified. One study indicated that the knockdown of METTL3 or METTL14 in $\mathrm{CD}^{+}{ }^{+} \mathrm{T}$ cells with short hairpin RNA (shRNA) could promote Tfh development upon lymphocytic choriomeningitis virus (LCMV) infection (42). However, other studies reported an opposite phenotype and pointed out that conditional ablation of METTL3 in $\mathrm{CD}^{+} \mathrm{T}$ cells dampened $\mathrm{Tfh}$ differentiation, proliferation, and survival ability after LCMV challenge (43). Notably, the latter study indicated that METTL3-mediated $\mathrm{m}^{6} \mathrm{~A}$ modification of transcription factor 7 (TCF7) mRNA can stabilize the transcript, and therefore maintain protein expression of TCF7 to initiate and secure the differentiation of Tfh cells (43). This regulatory mechanism differs with naïve $\mathrm{CD}^{+} \mathrm{T}$ cells or Tregs, where METTL3-directed $\mathrm{m}^{6} \mathrm{~A}$ modification decreases mRNA stabilization $(38,40)$. The divergent functional outcome of $\mathrm{m}^{6} \mathrm{~A}$ modification mainly depends on diverse $\mathrm{m}^{6} \mathrm{~A}$ "readers" in a cell type and cellular context-dependent fashion. Therefore, a deeper evaluation of the phenotypic effects of different $\mathrm{m}^{6} \mathrm{~A}$-readers will advance our knowledge of the $\mathrm{m}^{6} \mathrm{~A}$ machinery.

$\mathrm{m}^{6} \mathrm{~A}$ methylation may modulate $\mathrm{T}$ cells either directly or indirectly by affecting the function of antigen-presenting cells (APCs) $(44,45)$. In YTHDF1-deficient mice, the antigen-specific $\mathrm{CD}^{+} \mathrm{T}$ cell antitumor response increased compared with wildtype mice, relying on enhanced cross-presentation of tumor antigens and cross-priming of $\mathrm{CD}^{+} \mathrm{T}$ cells by classical dendritic cells (cDCs) (44). Furthermore, METTL3-specific deficiency in DCs led to phenotypic and functional maturation defects, causing a reduction in levels of co-stimulatory molecules CD40, CD80, and cytokine IL-12, and reduced the ability to stimulate $\mathrm{CD}^{+} \mathrm{T}$ cell responses (45). These findings raise the possibility of exploiting $\mathrm{m}^{6} \mathrm{~A}$ methylation to promote $\mathrm{DC}$ activation and DC-based $\mathrm{T}$ cell responses. However, whether the $\mathrm{m}^{6} \mathrm{~A}$ machinery directly regulates the development and function of $\mathrm{CD}^{+} \mathrm{T}$ cells has yet to be determined.

Although current studies have highlighted the importance of $\mathrm{m}^{6} \mathrm{~A}$ in governing $\mathrm{T}$ cell functions, it seems that these have only focused on better defining the role of the "writers" or "readers" (Figure 1). It will be intriguing to characterize whether and how "erasers" control T cell homeostasis or functionality. It has been reported that dopamine receptors expressed in T cells are critical for instructing thymic $\mathrm{T}$ cell development and maintaining $\mathrm{T}$ cell function $(46,47)$. Interestingly, FTO can also participate in the dopamine signaling pathway (48); thus, it remains a possibility that FTO may affect $\mathrm{T}$ cell homeostasis or function via dopamine receptors. Recent studies have excluded the potential role of ALKBH5 in directing Tfh differentiation upon LCMV infection using shRNA-mediated knockdown of ALKBH5 (42). However, based on results obtained from macrophages, it has been suggested that ALKBH5 demethylates $\alpha$-ketoglutarate dehydrogenase $(\mathrm{OGDH})$ transcript, increases its mRNA stability and protein expression, and metabolically promotes viral replication in macrophage (49), which still raises the possibility of ALKBH5 in maintaining $\mathrm{T}$ cell function and warrants additional investigation.

\section{$N^{6}$-2'-O-dimethyladenosine ( $\left.m^{6} \mathrm{Am}\right)$}

$\mathrm{m}^{6} \mathrm{Am}$ refers to the terminal modification of the first nucleotide after the mRNA 5'cap, and was first identified in animal cells and viral mRNA in 1975 (50). Usually, if this first nucleotide is 2-Omethyladenosine (Am), it can be further methylated at the nitrogen- 6 position to form $\mathrm{m}^{6} \mathrm{Am}$ (50). Like $\mathrm{m}^{6} \mathrm{~A}, \mathrm{~m}^{6} \mathrm{Am}$ is also dynamically regulated by methyltransferase and demethylase $(51,52)$. Phosphorylated CTD interacting factor 1 (PCIF1) is the only evolutionarily conserved methyltransferase for $\mathrm{m}^{6} \mathrm{Am}$, and depleting PCIF1 leads to the deficiency of $\mathrm{m}^{6} \mathrm{Am}$ alone without affecting $\mathrm{m}^{6} \mathrm{~A}$ levels or distribution (52-54). The function of PCIF1 is still controversial as one study indicated the loss of PCIF1 did not affect mRNA translation but reduced stability of a subset of $\mathrm{m}^{6} \mathrm{Am}$-annotated mRNAs (52), while another reported that PCIF1 suppressed protein translation without influencing mRNA stability (55). The inconsistency may result from the different experimental systems used to dissect the effects of $\mathrm{m}^{6} \mathrm{Am}$ on translation, thus, it remains to be determined whether this effect is maintained, diminished, or enhanced under various biological circumstances.

Contrary to the specificity of ALKBH5 toward $\mathrm{m}^{6} \mathrm{~A}$ modification, FTO shows wide reversible demethylation activity, and functions as a demethylase for the $\mathrm{m}^{6} \mathrm{Am}$ modification to reduce the stability of target mRNAs, preferentially demethylating $\mathrm{m}^{6} \mathrm{Am}$ rather than $\mathrm{m}^{6} \mathrm{~A}(26,56)$ (Table 1). Considering the possible role of FTO in maintaining $\mathrm{T}$ cell development or function (48), additional studies are needed to characterize $\mathrm{m}^{6} \mathrm{Am}$ 's function in orchestrating $\mathrm{T}$ cell immunity. 


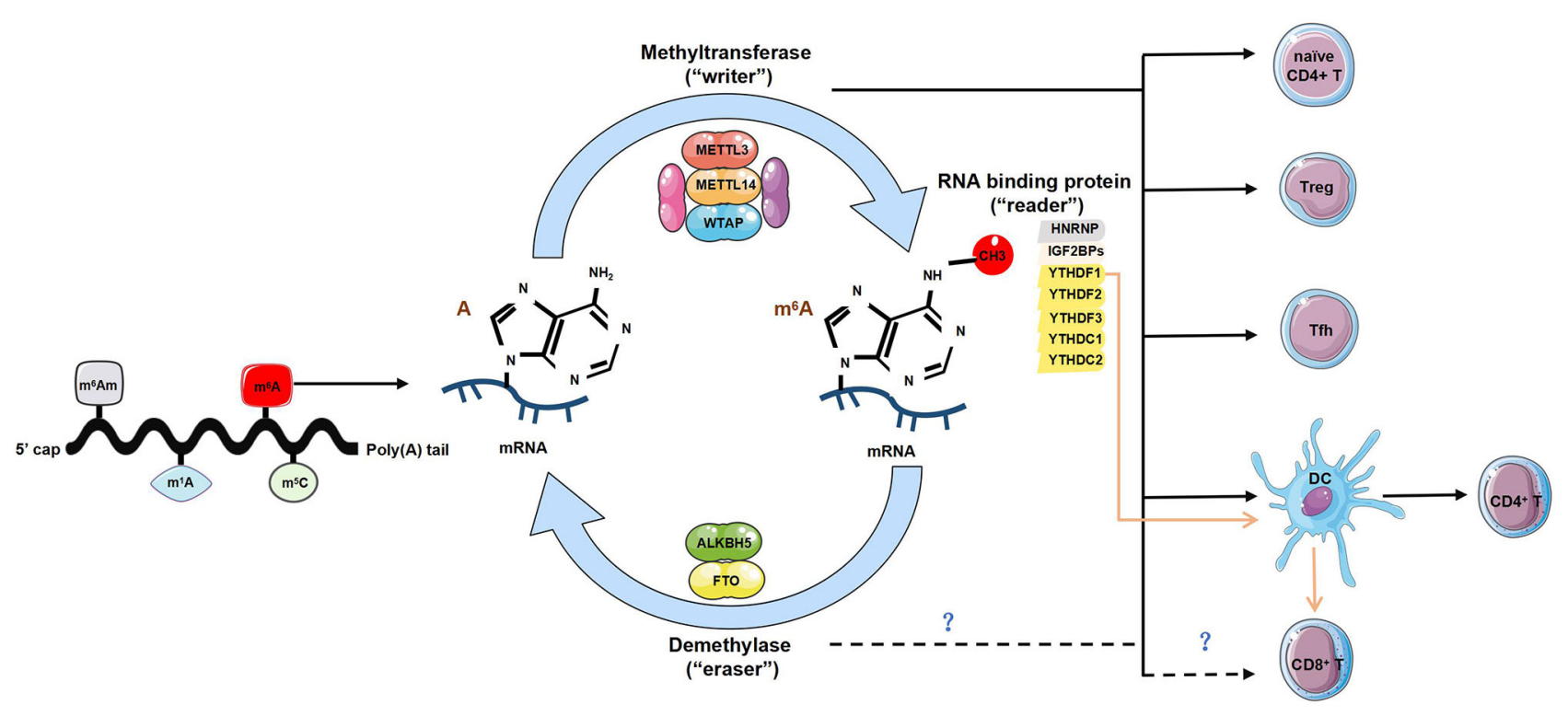

FIGURE 1 | The regulatory role of $m^{6} A$ modification in T cells. Diverse forms of RNA methylation have been identified on mRNAs, mainly involving $N^{6}$ methyladenosine $\left(m^{6} \mathrm{~A}\right), N^{6}-2^{\prime}$-O-dimethyladenosine $\left(\mathrm{m}^{6} \mathrm{Am}\right), N^{1}$-methyladenosine $\left(\mathrm{m}^{1} \mathrm{~A}\right)$ and 5 -methylcytosine $\left(\mathrm{m}^{5} \mathrm{C}\right) . \mathrm{m}^{6} \mathrm{~A}$ modification is reversibly installed and removed by methyltransferases ("writers") and demethylases ("erasers"). Multiple proteins that bind to $\mathrm{m}^{6} \mathrm{~A}$ to affect the fate of RNA are referred to as $\mathrm{m}^{6} \mathrm{~A}$-binding proteins ("readers"). The "writers" complex is mainly composed of METLL13, METTL14 and WTAP, can directly modulate T cells by maintaining homeostasis of naiive $\mathrm{CD}_{4}^{+} \mathrm{T}$ cells, promoting the function of regulatory $\mathrm{T}$ cells (Tregs) and $\mathrm{T}$ follicular helper (Tfh) cells. It also indirectly enhances $\mathrm{CD} 4^{+} \mathrm{T}$ cells function via promoting dendritic cell (DCs) activation and DC-based T cell response. The "readers" involve YTHDF1-3, YTHDC1-2, HNRNP and IGF2BPs. The lack of YTHDF1 can enhance antigen-specific CD8 ${ }^{+} T$ cell antitumor response indirectly by the increased cross-priming of CD8 ${ }^{+} \mathrm{T}$ cells by DCs. However, whether the "writers" and "readers" directly regulates the development and function of CD8 ${ }^{+} \mathrm{T}$ cells is unknown. The current identified two "erasers" are FTO and ALKBH5, whether and how "erasers" control T cell homeostasis or functionality is yet to be determined.

\section{$N^{1}$-methyladenosine $\left(m^{1} A\right)$}

The methylation on the nitrogen-1 position of adenosine to form $\mathrm{m}^{1} \mathrm{~A}$ was first identified in tRNA (57). This modification is typically found at position 58 in the T-loop of tRNA ( $\left.{ }^{1} \mathrm{~A} 58\right)$ $(58,59)$. The $\mathrm{m}^{1} \mathrm{~A}$ modification on tRNA is of great importance for tRNA folding, stability, and tRNA-protein interaction (6062). $\mathrm{m}^{1} \mathrm{~A}$ has also been detected in rRNA and affects the tertiary structure of ribosomes and the translation of downstream genes $(63,64)$. Subsequently, the rare presence of $\mathrm{m}^{1} \mathrm{~A}$ sites in mRNA and $\operatorname{lncRNA}$ was also reported $(65,66)$. Recent findings suggest that $\mathrm{m}^{1} \mathrm{~A}$ at the coding sequence (CDS) in mitochondrial messenger RNA (mt-mRNA) blocks the effective translation of modified codons $(66,67)$. Moreover, ribosome profiling data indicate that $\mathrm{m}^{1} \mathrm{~A}$ in nuclear mRNA might promote translation (67). However, the exact function of $\mathrm{m}^{1} \mathrm{~A}$ in these RNAs still need further investigation.

$\mathrm{m}^{1} \mathrm{~A}$, as a reversible RNA modification, is catalyzed by methyltransferases including tRNA methyltransferase 6/61A (TRMT6/61A), TRMT61B, TRMT10C, and Nucleomethylin (NML), and by demethylases FTO, ALKBH1, and ALKBH3 (26, 58, 59, 67-70). YTHDF1-3 and YTHDC1 have been reported as the "readers" of $\mathrm{m}^{1} \mathrm{~A}$ (71) (Table 1). TRMT6/61A is responsible for the modification of a series of $\mathrm{m}^{1} \mathrm{~A}$ sites in tRNA and lncRNA, recognizing the substrate RNA mainly through a strong $\mathrm{T}$-loop structure typically comprising a 5-base pair (bp) stem and a 7-bp loop $(67,72)$. TRMT61B, as a mitochondrial-specific tRNA methyltransferase, has been reported to catalyze $\mathrm{m}^{1} \mathrm{~A}$ modification in both tRNA and rRNAs $(73,74)$. TRMT10C can catalyze $\mathrm{m}^{1} \mathrm{~A}$ modification in mitochondrial coding transcripts $(75,76)$, and NML will catalyze the formation of $\mathrm{m}^{1} \mathrm{~A}$ at multiple rRNA sites both in human and mouse cells (77). Although distinct tRNA expression patterns and dynamic changes involving tRNA modification occur in early mouse $\mathrm{CD} 4^{+} \mathrm{T}$ cells activation, the $\mathrm{m}^{1} \mathrm{~A}$ modification at position 58 of tRNA remains constant throughout this process (78), questioning whether $\mathrm{m}^{1} \mathrm{~A}$ may regulate $\mathrm{T}$ cell activation. Therefore, uncovering the biological consequences of $\mathrm{m}^{1} \mathrm{~A}$ under various physiological and pathological conditions in $\mathrm{T}$ cells will be critical to improve our understanding of the role that $\mathrm{m}^{1} \mathrm{~A}$ machinery plays in regulating $\mathrm{T}$ cell immunity.

\section{5-Methylcytosine $\left(\mathrm{m}^{5} \mathrm{C}\right)$}

The existence of $\mathrm{m}^{5} \mathrm{C}$ in RNAs has been known since the $1970 \mathrm{~s}$ $(79,80)$. High throughput detection methods identified $\mathrm{m}^{5} \mathrm{C}$ as an abundant RNA modification in diverse RNA species, including mRNA, tRNA, rRNA, and other ncRNAs (81). Like $\mathrm{m}^{6} \mathrm{~A}$, the $\mathrm{m}^{5} \mathrm{C}$ modification in RNA is also catalyzed by "writers", including DNA methyltransferase homologs and members of the NOL1/NOP2/SUN domain (NSUN) family proteins (including NSUN1-7) and DNA methyltransferase (DNMT) homologue 
DNMT2 (81-84), and "readers" like Aly/REF export factor (ALYREF) (85) and Y-box binding protein 1(YBX1) (86). However, the "erasers" of $\mathrm{m}^{5} \mathrm{C}$ in RNAs have not yet been identified (Table 1) $\mathrm{m}^{5} \mathrm{C}$ has emerged as a critical regulator involved in modulating the export and stability of RNA, ribosome assembly, and translation $(81,87)$. However, the specific gene signatures of $\mathrm{m}^{5} \mathrm{C}$-related regulators in $\mathrm{T}$ cell immunity remain largely unknown.

A recent study has reported reduced $\mathrm{mRNA} \mathrm{m}^{5} \mathrm{C}$ levels in $\mathrm{CD} 4^{+} \mathrm{T}$ cells from patients with systemic lupus erythematosus (SLE) compared with $\mathrm{CD}^{+} \mathrm{T}$ cells of healthy controls (HCs) (88). NSUN2 is the only known mRNA $\mathrm{m}^{5} \mathrm{C}$ methyltransferase (75) and whose mRNA and protein expression is reduced dramatically in $\mathrm{CD}^{+} \mathrm{T}$ cells from SLE patients relative to HCs (88). Importantly, $\mathrm{m}^{5} \mathrm{C}$ hypomethylated transcripts in SLE stable groups or SLE moderate/major active groups have shown obvious enrichment of eukaryotic translation elongation and protein methylation (88). In addition, up-regulated genes presenting an abundance of $\mathrm{m}^{5} \mathrm{C}$ has been described to be involved in the flares and remission of SLE patients, and subsequent damage to the patient's immune system (88). This study suggested the relevance of aberrant $\mathrm{m}^{5} \mathrm{C}$ mRNA modification in vital immune pathways of $\mathrm{CD} 4^{+} \mathrm{T}$ cells from SLE patients, but how the "writer" NSUN2 contributes to the $\mathrm{m}^{5} \mathrm{C}$ epitranscriptomic code during SLE is still unclear. Further studies are needed to acquire a better understanding of the role of NSUN2 in patients with SLE. Notably, other RNA methylations, such as 3-methylcytidine $\left(\mathrm{m}^{3} \mathrm{C}\right), N^{1}$-methylguanosine $\left(\mathrm{m}^{1} \mathrm{G}\right), 5$ methyluridine $\left(\mathrm{m}^{5} \mathrm{U}\right)$ have also been mapped in $\mathrm{CD}^{+} \mathrm{T}$ cells (88), and it would be interesting to explore whether these modifications exert a similar regulatory role with $\mathrm{m}^{6} \mathrm{~A}$ in maintaining $\mathrm{T}$ cell homeostasis in the future.

\section{CONCLUDING REMARKS}

As a critical component of epigenetics, posttranscriptional RNA methylation provides abundant possibilities for different physiological and pathological processes relevant to $\mathrm{T}$ cells. Based on the complex self-regulatory processes in $\mathrm{T}$ cells, major knowledge gaps remain to be filled in this developing field. Studies in mice have deciphered the significance of $\mathrm{m}^{6} \mathrm{~A}$ methylation as a "brake" to modulate transcription during $\mathrm{T}$ cell activation (38). Although many $\mathrm{m}^{6} \mathrm{~A}$ sites have been detected on $\mathrm{T}$ cells, whether these sites are subject to an equal contribution from the action of "writers" and "erasers" needs to be further

\section{REFERENCES}

1. Nachtergaele $\mathrm{S}, \mathrm{He} \mathrm{C}$. Chemical modifications in the life of an mRNA transcript. Annu Rev Genet (2018) 52:349-72. doi: 10.1146/annurev-genet120417-031522

2. Helm M, Motorin Y. Detecting RNA modifications in the epitranscriptome: predict and validate. Nat Rev Genet (2017) 18:275-91. doi: 10.1038/ nrg.2016.169 determined. Further, considering the importance of "writers" in maintaining $\mathrm{T}$ cell function, the role of $\mathrm{m}^{6} \mathrm{~A}$ "erasers" in governing $\mathrm{T}$ cell homeostasis and function remains to be elucidated. Future studies are required to answer whether a selectivity and asymmetry in the actions of $\mathrm{m}^{6} \mathrm{~A}$ "writers" and "erasers" is active in controlling $\mathrm{T}$ cell function.

Since our observations regarding the cross-talk between RNA modifications in colorectal cancer highlighted their therapeutic liability toward immunotherapy (89), it would be interesting to decipher the existence of a similar complex regulatory network in T cells, and to determine whether other RNA methylations might function as a sort of "gas pedal" or "pace keeper" to control T cell clonal expansion, differentiation, and subsequent effector functions. The identification of a specific RNA epigenetic translational checkpoint will advance our knowledge concerning how different RNA methylations are sequentially coordinated to regulate $\mathrm{T}$ cell immunity. Moreover, a proper investigation with the objective to explain why and under which conditions $\mathrm{T}$ cells rely on different types of RNA methylations to regulate gene expression will be a major step forward. Future explorations will reveal novel therapeutic targets by exploiting RNA methylations to alleviate $\mathrm{T}$ cell-related inflammatory diseases, infections, and to promote cancer immunotherapy.

\section{AUTHOR CONTRIBUTIONS}

YC drafted the manuscript. HBL and JZ designed the review, wrote, and revised the manuscript. All authors contributed to the article and approved the submitted version.

\section{FUNDING}

This work was supported by the National Natural Science Foundation of China (91753141/82030042/32070917 to HBL, 81901569 to JZ), Shanghai Science and Technology Committee (20JC1417400/201409005500/20JC1410100 to HBL), the Postdoctoral Innovation Talent Support Program (BX20190214 to JZ), the Shanghai Super Postdoctoral Program (JZ), China Postdoctoral Science Foundation (2020M671149 to JZ), the Program for Professor of Special Appointment (Eastern Scholar) at Shanghai Institutions of Higher Learning (HBL), the start-up fund from the Shanghai Jiao Tong University School of Medicine (HBL). 
6. Shulman Z, Stern-Ginossar N. The RNA modification N 6-methyladenosine as a novel regulator of the immune system. Nat Immunol (2020) 21:501-12. doi: 10.1038/s41590-020-0650-4

7. Zhang $\mathrm{C}, \mathrm{Fu}$ J, Zhou Y. A review in research progress concerning $\mathrm{m} 6 \mathrm{~A}$ methylation and immunoregulation. Front Immunol (2019) 10:922. doi: 10.3389/fimmu.2019.00922

8. Gleeson M, Bishop NC. The T cell and NK cell immune response. Ann Transplant (2005) 10:44-9.

9. Dermime S, Gilham DE, Shaw DM, Davidson EJ, Meziane E-K, Armstrong A, et al. Vaccine and antibody-directed T cell tumour immunotherapy. Biochim Biophys Acta (BBA) Reviews Cancer (2004) 1704:11-35. doi: 10.1016/ j.bbcan.2004.03.002

10. Roundtree IA, Evans ME, Pan T, He C. Dynamic RNA modifications in gene expression regulation. Cell (2017) 169:1187-200. doi: 10.1016/j.cell.2017.05.045

11. Sergiev PV, Aleksashin NA, Chugunova AA, Polikanov YS, Dontsova OA. Structural and evolutionary insights into ribosomal RNA methylation. Nat Chem Biol (2018) 14:226. doi: 10.1038/nchembio.2569

12. Romano G, Veneziano D, Nigita G, Nana-Sinkam SP. RNA methylation in ncRNA: classes, detection, and molecular associations. Front Genet (2018) 9:243. doi: 10.3389/fgene.2018.00243

13. Frye M, Harada BT, Behm M, He C. RNA modifications modulate gene expression during development. Science (2018) 361:1346-9. doi: 10.1126/ science.aau1646

14. Desrosiers R, Friderici K, Rottman F. Identification of methylated nucleosides in messenger RNA from Novikoff hepatoma cells. Proc Natl Acad Sci U States A (1974) 71:3971-5. doi: 10.1073/pnas.71.10.3971

15. Perry RP, Kelley DE. Existence of methylated messenger RNA in mouse L cells. Cell (1974) 1:37-42. doi: 10.1016/0092-8674(74)90153-6

16. Wei CM, Gershowitz A, Moss B. Methylated nucleotides block 5 ' terminus of HeLa cell messenger RNA. Cell (1975) 4:379-86. doi: 10.1016/0092-8674(75) 90158-0

17. Tong J, Flavell RA, Li H-B. RNA m 6 A modification and its function in diseases. Front Med (2018) 12:481-9. doi: 10.1007/s11684-018-0654-8

18. Bokar JA, Shambaugh ME, Polayes D, Matera AG, Rottman FM. Purification and CDNA cloning of the AdoMet-binding subunit of the human mRNA (N6adenosine)-methyltransferase. RNA (1997) 3:1233-47.

19. Hongay CF, Orr-Weaver TL. Drosophila inducer of MEiosis 4 (IME4) is required for Notch signaling during oogenesis. Proc Natl Acad Sci U States A (2011) 108:14855-60. doi: 10.1073/pnas.1111577108

20. Liu J, Yue Y, Han D, Wang X, Fu Y, Zhang L, et al. A METTL3-METTL14 complex mediates mammalian nuclear RNA N6-adenosine methylation. Nat Chem Biol (2014) 10:93-5. doi: 10.1038/nchembio.1432

21. Wang Y, Li Y, Toth JI, Petroski MD, Zhang Z, Zhao JC. N6 -methyladenosine modification destabilizes developmental regulators in embryonic stem cells. Nat Cell Biol (2014) 16:191-8. doi: 10.1038/ncb2902

22. Ping XL, Sun BF, Wang L, Xiao W, Yang X, Wang WJ, et al. Mammalian WTAP is a regulatory subunit of the RNA N6-methyladenosine methyltransferase. Cell Res (2014) 24:177-89. doi: 10.1038/cr.2014.3

23. Zhong S, Li H, Bodi Z, Button J, Vespa L, Herzog M, et al. MTA is an Arabidopsis messenger RNA adenosine methylase and interacts with a homolog of a sex-specific splicing factor. Plant Cell (2008) 20:1278-88. doi: $10.1105 /$ tpc. 108.058883

24. Jia G, Fu Y, Zhao X, Dai Q, Zheng G, Yang Y, et al. N6-Methyladenosine in nuclear RNA is a major substrate of the obesity-associated FTO. Nat Chem Biol (2011) 7:885-7. doi: 10.1038/nchembio.687

25. Zheng G, Dahl JA, Niu Y, Fedorcsak P, Huang CM, Li CJ, et al. ALKBH5 Is a Mammalian RNA Demethylase that Impacts RNA Metabolism and Mouse Fertility. Mol Cell (2013) 49:18-29. doi: 10.1016/j.molcel.2012.10.015

26. Wei J, Liu F, Lu Z, Fei Q, Ai Y, He PC, et al. Differential m6A, m6Am, and m1A demethylation mediated by FTO in the cell nucleus and cytoplasm. Mol Cell (2018) 71:973-85. doi: 10.1016/j.molcel.2018.08.011

27. Dominissini D, Moshitch-Moshkovitz S, Schwartz S, Salmon-Divon M, Ungar L, Osenberg S, et al. Topology of the human and mouse m6A RNA methylomes revealed by m6A-seq. Nature (2012) 485:201-6. doi: 10.1038/ nature11112

28. Zhu T, Roundtree IA, Wang P, Wang X, Wang L, Sun C, et al. Crystal structure of the YTH domain of YTHDF2 reveals mechanism for recognition of N6-methyladenosine. Cell Res (2014) 24:1493-6. doi: 10.1038/cr.2014.152
29. Wang X, Zhao BS, Roundtree IA, Lu Z, Han D, Ma H, et al. N6methyladenosine modulates messenger RNA translation efficiency. Cell (2015) 161:1388-99. doi: 10.1016/j.cell.2015.05.014

30. Alarcón CR, Goodarzi H, Lee H, Liu X, Tavazoie S, Tavazoie SF. HNRNPA2B1 Is a Mediator of m6A-Dependent Nuclear RNA Processing Events. Cell (2015) 162:1299-308. doi: 10.1016/j.cell.2015.08.011

31. Liu N, Dai Q, Zheng G, He C, Parisien M, Pan T. N6 -methyladenosinedependent RNA structural switches regulate RNA-protein interactions. Nature (2015) 518:560-4. doi: 10.1038/nature14234

32. Liu N, Zhou KI, Parisien M, Dai Q, Diatchenko L, Pan T. N6-methyladenosine alters RNA structure to regulate binding of a low-complexity protein. Nucleic Acids Res (2017) 45:6051-63. doi: 10.1093/nar/gkx141

33. Huang H, Weng H, Sun W, Qin X, Shi H, Wu H, et al. Recognition of RNA N 6 -methyladenosine by IGF2BP proteins enhances mRNA stability and translation. Nat Cell Biol (2018) 20:285-95. doi: 10.1038/s41556-018-0045-z

34. Zhou KI, Pan T. An additional class of $\mathrm{m} 6$ A readers. Nat Cell Biol (2018) 20:230-2. doi: 10.1038/s41556-018-0046-y

35. Wilson CB, Rowell E, Sekimata M. Epigenetic control of T-helper-cell differentiation. Nat Rev Immunol (2009) 9:91-105. doi: 10.1038/nri2487

36. Davenport MP, Smith NL, Rudd BD. Building a T cell compartment: how immune cell development shapes function. Nat Rev Immunol (2020) 20:499506. doi: 10.1038/s41577-020-0332-3

37. Batista PJ, Molinie B, Wang J, Qu K, Zhang J, Li L, et al. m6A RNA modification controls cell fate transition in mammalian embryonic stem cells. Cell Stem Cell (2014) 15:707-19. doi: 10.1016/j.stem.2014.09.019

38. Li H-B, Tong J, Zhu S, Batista PJ, Duffy EE, Zhao J, et al. m 6 A mRNA methylation controls $\mathrm{T}$ cell homeostasis by targeting the IL-7/STAT5/SOCS pathways. Nature (2017) 548:338-42. doi: 10.1038/nature23450

39. Furlan M, Galeota E, De Pretis S, Caselle M, Pelizzola M. m6A-dependent RNA dynamics in T cell differentiation. Genes (2019) 10:28. doi: 10.3390/ genes 10010028

40. Tong J, Cao G, Zhang T, Sefik E, Vesely MCA, Broughton JP, et al. m 6 A mRNA methylation sustains Treg suppressive functions. Cell Res (2018) 28:253-6. doi: 10.1038/cr.2018.7

41. Crotty S. Follicular helper CD4 T cells (Tfh). Annu Rev Immunol (2011) 29:621-63. doi: 10.1146/annurev-immunol-031210-101400

42. Zhu Y, Zhao Y, Zou L, Zhang D, Aki D, Liu Y-C. The E3 ligase VHL promotes follicular helper $\mathrm{T}$ cell differentiation via glycolytic-epigenetic control. $J$ Exp Med (2019) 216:1664-81. doi: 10.1084/jem.20190337

43. Yao Y, Yang Y, Guo W, Xu L, You M, Zhang Y-C, et al. METTL3-dependent $\mathrm{m} 6$ A modification programs $\mathrm{T}$ follicular helper cell differentiation. Nat Commun (2021) 12:1-16. doi: 10.1038/s41467-021-21594-6

44. Han D, Liu J, Chen C, Dong L, Liu Y, Chang R, et al. Anti-tumour immunity controlled through mRNA m 6 A methylation and YTHDF1 in dendritic cells. Nature (2019) 566:270-4. doi: 10.1038/s41586-019-0916-x

45. Wang H, Hu X, Huang M, Liu J, Gu Y, Ma L, et al. Mettl3-mediated mRNA m (6)A methylation promotes dendritic cell activation. Nat Commun (2019) 10:1898. doi: 10.1038/s41467-019-09903-6

46. Mignini F, Sabbatini M, Capacchietti M, Amantini C, Bianchi E, Artico M, et al. T-cell subpopulations express a different pattern of dopaminergic markers in intra-and extra-thymic compartments. J Biol Regul Homeost Agents (2013) 27:463-75.

47. Huang Y, Qiu A-W, Peng Y-P, Liu Y, Huang H-W, Qiu Y-H. Roles of dopamine receptor subtypes in mediating modulation of $\mathrm{T}$ lymphocyte function. Neuroendocrinol Lett (2010) 31:782.

48. Hess ME, Hess S, Meyer KD, Verhagen LA, Koch L, Brönneke HS, et al. The fat mass and obesity associated gene (Fto) regulates activity of the dopaminergic midbrain circuitry. Nat Neurosci (2013) 16:1042-8. doi: 10.1038/nn.3449

49. Liu Y, You Y, Lu Z, Yang J, Li P, Liu L, et al. N6-methyladenosine RNA modification-mediated cellular metabolism rewiring inhibits viral replication. Science (2019) 365:1171-6. doi: 10.1126/science.aax4468

50. Wei C-M, Gershowitz A, Moss BN. 6, O 2'-dimethyladenosine a novel methylated ribonucleoside next to the $5^{\prime}$ terminal of animal cell and virus mRNAs. Nature (1975) 257:251-3. doi: 10.1038/257251a0

51. Mauer J, Luo X, Blanjoie A, Jiao X, Grozhik AV, Patil DP, et al. Reversible methylation of $\mathrm{m} 6 \mathrm{~A} \mathrm{~m}$ in the $5^{\prime}$ cap controls mRNA stability. Nature (2017) 541:371-5. doi: 10.1038/nature21022 
52. Boulias K, Toczydłowska-Socha D, Hawley BR, Liberman N, Takashima K, Zaccara S, et al. Identification of the m6Am methyltransferase PCIF1 reveals the location and functions of m6Am in the transcriptome. Mol Cell (2019) 75:631-43. doi: 10.1016/j.molcel.2019.06.006

53. Sun H, Zhang M, Li K, Bai D, Yi C. Cap-specific, terminal N 6-methylation by a mammalian m 6 Am methyltransferase. Cell Res (2019) 29:80-2. doi: 10.1038/s41422-018-0117-4

54. Li K, Cai J, Zhang M, Zhang X, Xiong X, Meng H, et al. Landscape and regulation of $\mathrm{m} 6 \mathrm{~A}$ and $\mathrm{m} 6 \mathrm{Am}$ methylome across human and mouse tissues. Mol Cell (2020) 77:426-440. e6. doi: 10.1016/j.molcel.2019.09.032

55. Sendinc E, Valle-Garcia D, Dhall A, Chen H, Henriques T, Sheng W, et al. PCIF1 catalyzes m6Am mRNA methylation to regulate gene expression. $\mathrm{Mol}$ Cell (2019) 75:620-30. doi: 10.1016/j.molcel.2019.05.030

56. Zhao X, Yang Y, Sun B-F, Shi Y, Yang X, Xiao W, et al. FTO-dependent demethylation of N6-methyladenosine regulates mRNA splicing and is required for adipogenesis. Cell Res (2014) 24:1403-19. doi: 10.1038/cr.2014.151

57. RajBhandary UL, Stuart A, Faulkner RD, Chang SH, Khorana HG. Nucleotide sequence studies on yeast phenylalanine sRNA. Cold Spring Harb Symp Quant Biol (1966) 31:425-34. doi: 10.1101/SQB.1966.031.01.055

58. Li X, Xiong X, Wang K, Wang L, Shu X, Ma S, et al. Transcriptome-wide mapping reveals reversible and dynamic $\mathrm{N}(1)$-methyladenosine methylome. Nat Chem Biol (2016) 12:311-6. doi: 10.1038/nchembio.2040

59. Dominissini D, Nachtergaele S, Moshitch-Moshkovitz S, Peer E, Kol N, BenHaim MS, et al. The dynamic N(1)-methyladenosine methylome in eukaryotic messenger RNA. Nature (2016) 530:441-6. doi: 10.1038/nature16998

60. Degut C, Ponchon L, Folly-Klan M, Barraud P, Tisne C. The m1A(58) modification in eubacterial tRNA: An overview of tRNA recognition and mechanism of catalysis by TrmI. Biophys Chem (2016) 210:27-34. doi: 10.1016/j.bpc.2015.06.012

61. Oerum S, Dégut C, Barraud P, Tisné C. m1A post-transcriptional modification in tRNAs. Biomolecules (2017) 7:20. doi: 10.3390/biom7010020

62. El Yacoubi B, Bailly M, De Crécy-Lagard V. Biosynthesis and function of posttranscriptional modifications of transfer RNAs, in. Annu Rev Genet (2012) p:69-95. doi: 10.1146/annurev-genet-110711-155641

63. Peifer C, Sharma S, Watzinger P, Lamberth S, Kotter P, Entian KD. Yeast Rrp8p, a novel methyltransferase responsible for m1A 645 base modification of 25S rRNA. Nucleic Acids Res (2013) 41:1151-63. doi: 10.1093/nar/gks1102

64. Sharma S, Watzinger P, Kötter P, Entian KD. Identification of a novel methyltransferase, Bmt2, responsible for the N-1-methyl-adenosine base modification of 25S rRNA in Saccharomyces cerevisiae. Nucleic Acids Res (2013) 41:5428-43. doi: 10.1093/nar/gkt195

65. Grozhik AV, Olarerin-George AO, Sindelar M, Li X, Gross SS, Jaffrey SR. Antibody cross-reactivity accounts for widespread appearance of $\mathrm{m} 1 \mathrm{~A}$ in 5'UTRs. Nat Commun (2019) 10:1-13. doi: 10.1038/s41467-019-13146-w

66. Safra M, Sas-Chen A, Nir R, Winkler R, Nachshon A, Bar-Yaacov D, et al. The m 1 A landscape on cytosolic and mitochondrial mRNA at single-base resolution. Nature (2017) 551:251-5. doi: 10.1038/nature24456

67. Li X, Xiong X, Zhang M, Wang K, Chen Y, Zhou J, et al. Base-resolution mapping reveals distinct $\mathrm{m} 1 \mathrm{~A}$ methylome in nuclear-and mitochondrial-encoded transcripts. Mol Cell (2017) 68:993-1005. e9. doi: 10.1016/j.molcel.2017.10.019

68. Liu F, Clark W, Luo G, Wang X, Fu Y, Wei J, et al. ALKBH1-Mediated tRNA Demethylation Regulates Translation. Cell (2016) 167:1897. doi: 10.1016/ j.cell.2016.11.045

69. Nachtergaele S, He C. Chemical Modifications in the Life of an mRNA Transcript. Annu Rev Genet (2018) 52:349-72. doi: 10.1146/annurev-genet-120417-031522

70. Peer E, Moshitch-Moshkovitz S, Rechavi G, Dominissini D. The Epitranscriptome in Translation Regulation. Cold Spring Harb Perspect Biol (2019) 11:a032623. doi: 10.1101/cshperspect.a032623

71. Dai X, Wang T, Gonzalez G, Wang Y. Identification of YTH Domaincontaining proteins as the readers for N 1-Methyladenosine in RNA. Anal Chem (2018) 90:6380-4. doi: 10.1021/acs.analchem.8b01703

72. Safra M, Sas-Chen A, Nir R, Winkler R, Nachshon A, Bar-Yaacov D, et al. The m1A landscape on cytosolic and mitochondrial mRNA at single-base resolution. Nature (2017) 551:251-5. doi: 10.1038/nature24456

73. Bar-Yaacov D, Frumkin I, Yashiro Y, Chujo T, Ishigami Y, Chemla Y, et al. Mitochondrial 16S rRNA Is Methylated by tRNA Methyltransferase
TRMT61B in All Vertebrates. PloS Biol (2016) 14:e1002557. doi: 10.1371/ journal.pbio. 1002557

74. Chujo T, Suzuki T. Trmt61B is a methyltransferase responsible for 1methyladenosine at position 58 of human mitochondrial tRNAs. Rna (2012) 18:2269-76. doi: 10.1261/rna.035600.112

75. Li Q, Li X, Tang H, Jiang B, Dou Y, Gorospe M, et al. NSUN2-mediated m5C methylation and METTL3/METTL14-mediated m6A methylation cooperatively enhance p21 translation. J Cell Biochem (2017) 118:2587-98. doi: $10.1002 /$ jcb. 25957

76. Metodiev MD, Thompson K, Alston CL, Morris AAM, He L, Assouline Z, et al. Recessive Mutations in TRMT10C Cause Defects in Mitochondrial RNA Processing and Multiple Respiratory Chain Deficiencies. Am J Hum Genet (2016) 98:993-1000. doi: 10.1016/j.ajhg.2016.03.010

77. Waku T, Nakajima Y, Yokoyama W, Nomura N, Kako K, Kobayashi A, et al. NML-mediated rRNA base methylation links ribosomal subunit formation to cell proliferation in a p53-dependent manner. J Cell Sci jcs (2016) 129:238293. doi: $10.1242 /$ jcs. 183723

78. Rak R, Polonsky M, Eizenberg I, Dahan O, Friedman N, Pilpel Y. Dynamic changes in tRNA modifications and abundance during T-cell activation. bioRxiv (2020). doi: 10.1101/2020.03.14.991901

79. Dubin DT, Taylor RH. The methylation state of poly A-containing messenger RNA from cultured hamster cells. Nucleic Acids Res (1975) 2:1653-68. doi: $10.1093 /$ nar/2.10.1653

80. Perry RP, Kelley DE, Friderici K, Rottman F. The methylated constituents of L cell messenger RNA: evidence for an unusual cluster at the 5 ' terminus. Cell (1975) 4:387-94. doi: 10.1016/0092-8674(75)90159-2

81. Trixl L, Lusser A. The dynamic RNA modification 5-methylcytosine and its emerging role as an epitranscriptomic mark. Wiley Interdiscip Reviews: RNA (2019) 10:e1510. doi: 10.1002/wrna.1510

82. Reid R, Greene PJ, Santi DV. Exposition of a family of RNA m 5 C methyltransferases from searching genomic and proteomic sequences. Nucleic Acids Res (1999) 27:3138-45. doi: 10.1093/nar/27.15.3138

83. Jeltsch A, Ehrenhofer-Murray A, Jurkowski TP, Lyko F, Reuter G, Ankri S, et al. Mechanism and biological role of Dnmt2 in nucleic acid methylation. RNA Biol (2017) 14:1108-23. doi: 10.1080/15476286.2016.1191737

84. Goll MG, Kirpekar F, Maggert KA, Yoder JA, Hsieh C-L, Zhang X, et al. Methylation of tRNAAsp by the DNA methyltransferase homolog Dnmt2. Science (2006) 311:395-8. doi: 10.1126/science.1120976

85. Yang X, Yang Y, Sun BF, Chen YS, Xu JW, Lai WY, et al. 5-methylcytosine promotes mRNA export - NSUN2 as the methyltransferase and ALYREF as an $\mathrm{m}(5) \mathrm{C}$ reader. Cell Res (2017) 27:606-25. doi: 10.1038/cr.2017.55

86. Chen X, Li A, Sun B-F, Yang Y, Han Y-N, Yuan X, et al. 5-methylcytosine promotes pathogenesis of bladder cancer through stabilizing mRNAs. Nat Cell Biol (2019) 21:978-90. doi: 10.1038/s41556-019-0361-y

87. Bohnsack KE, Höbartner C, Bohnsack MT. Eukaryotic 5-methylcytosine (m5C) RNA methyltransferases: mechanisms, cellular functions, and links to disease. Genes (2019) 10:102. doi: 10.3390/genes10020102

88. Guo G, Wang H, Shi X, Ye L, Yan K, Chen Z, et al. Disease Activity-Associated Alteration of mRNA m5 C Methylation in CD4+ T Cells of Systemic Lupus Erythematosus. Front Cell Dev Biol (2020) 8:430. doi: 10.3389/fcell.2020.00430

89. Chen H, Yao J, Bao R, Dong Y, Zhang T, Du Y, et al. Cross-talk of four types of RNA modification writers defines tumor microenvironment and pharmacogenomic landscape in colorectal cancer. Mol cancer (2021) 20:121. doi: 10.1186/s12943-021-01322-w

Conflict of Interest: The authors declare that the research was conducted in the absence of any commercial or financial relationships that could be construed as a potential conflict of interest.

Copyright (C) 2021 Chao, Li and Zhou. This is an open-access article distributed under the terms of the Creative Commons Attribution License (CC BY). The use, distribution or reproduction in other forums is permitted, provided the original author(s) and the copyright owner(s) are credited and that the original publication in this journal is cited, in accordance with accepted academic practice. No use, distribution or reproduction is permitted which does not comply with these terms. 